\title{
Multiple malignancies in a female patient with common variable immunodeficiency syndrome
}

\author{
Milena Todorovic ${ }^{1,2}$, MD, PhD, Bela Balint ${ }^{3,4}, \mathrm{PhD}$, Bosko $\underline{\text { Andjelic }}^{1}$, MD, MA, Biljana Mihaljevic ${ }^{1,2}$, PhD
}

\begin{abstract}
We herein present the case of a 55-year-old woman with a previous history of malignancies - uterine adenocarcinoma, basal cell carcinoma (which occurred twice consecutively), recurrent respiratory infections due to common variable immunodeficiency (CVID), and systemic granulomatous disease diagnosed at a later age. The patient suffered from diffuse large B cell lymphoma (DLBCL), which was successfully treated with R-CHOP chemotherapy, and continued with immunoglobulin supplementation. The patient was free of lymphoma and infectious complications for over 20 months despite her persistent immunodeficiency, but eventually developed colorectal adenocarcinoma. To the best of our knowledge, this is the first reported case of CVID associated with multiple solid tumours and DLBCL.
\end{abstract}

Keywords: common variable immunodeficiency, diffuse large B cell lymphoma, multiple carcinomas

\section{INTRODUCTION}

Common variable immunodeficiency (CVID) is a diagnostic category of primary immunodeficiency that includes heterogeneous disorders defined by reduced levels of serum immunoglobin (Ig), impaired antibody responses to infection or vaccines, and increased incidence of infection. The typical immunophenotypic finding of CVID, with respect to T cells, is the inversion of $\mathrm{CD} 4 / \mathrm{CD} 8$ ratio, with significantly decreased absolute count of $\mathrm{CD}^{+}{ }^{+} \mathrm{T}$ cells and normal $\mathrm{CD} 8^{+} \mathrm{T}$ cell count. ${ }^{(1)}$

CVID is the most frequent human primary immunodeficiency, with an estimated prevalence of 1 in 25,000, and may present in early childhood or as an acquired form at a later age.(2) CVID patients are at an increased risk of granuloma formation and developing autoimmune diseases, and have a higher predisposition to benign lymphadenopathy and lymphoid malignancies, especially non-Hodgkin's lymphomas. ${ }^{(3,4)}$ The occurrence rate of lymphomas in CVID is approximately $10 \% .{ }^{(5)}$ However, solid tumours (e.g. thymoma, colorectal cancer, gastric carcinoma, skin cancer) rarely arise in the setting of CVID. ${ }^{(6)}$

Herein, we report the case of a female patient who was diagnosed with CVID in adulthood. She had a previous history of multiple solid tumours and developed diffuse large B cell lymphoma (DLBCL) five years after CVID was successfully treated. Colorectal adenocarcinoma was later diagnosed unexpectedly.

\section{CASE REPORT}

A 55-year-old woman was admitted to the Haematology Department in May 2009 with a diagnosis of aggressive DLBCL. Previous medical history revealed that, at 32 years old, the patient had developed uterine adenocarcinoma, which was treated surgically and consecutively with radiotherapy. She had basal cell carcinoma on two successive occasions in 2003 and 2004. In 2004, she suffered from recurrent bronchopneumonia, and in accordance with established criteria, ${ }^{(7)}$ a diagnosis of CVID was made.
Laboratory analysis showed normal white blood cell count $\left(7.1 \times 10^{9} / \mathrm{L}\right)$, with lymphopenia (lymphocyte $0.8 \times 10^{9} / \mathrm{L}$ ) and hypogammaglobulinaemia (IgG $2.5 \mathrm{~g} / \mathrm{L}$, normal range [NR] 7-16 g/L; IgA 0.26 g/L, NR 0.7-4 g/L; IgM 1.99 g/L, NR $0.4-2.4 \mathrm{~g} / \mathrm{L})$. Flow cytometric analysis of peripheral blood lymphocytes was in accordance with the CVID diagnosis, revealing normal circulating B cells and a decreased absolute T cell count (511 cells/ $\mu \mathrm{L}, \mathrm{NR} 1,084-2,822$ ) with inversion of CD4/CD8 ratio (CD4 ${ }^{+} \mathrm{T}$ cells 217 cells/ $\mu \mathrm{L}, \mathrm{NR} 703-1,588$ cells $/ \mu \mathrm{L} ; \mathrm{CD}^{+} \mathrm{T}$ cells 291 cells/ $\mu \mathrm{L}, \mathrm{NR} 259-1,150)$. The analysis of $C D 4^{+} \mathrm{T}$ cell subsets revealed significant predomination of the $\mathrm{CD} 4{ }^{+} \mathrm{CD} 45 \mathrm{RO}^{+}$ subpopulation (95\% per CD4+ $\mathrm{T}$ cells) over the $\mathrm{CD} 4{ }^{+} \mathrm{CD} 45 \mathrm{RA}^{+}$ subpopulation ( $5 \%$ per $\mathrm{CD} 4^{+} \mathrm{T}$ cells). Cytogenetic and molecular analyses did not confirm any chromosomal aberration or genetic disorder linked to hypogammaglobulinaemia. ${ }^{(7)}$ Clinical examination excluded drug-induced hypogammaglobulinaemia, the presence of infectious diseases, haematological malignancy and systemic disorder. ${ }^{(7)}$ A regular substitution therapy with intravenous immunoglobulin (IVIG) at a dose of $0.5 \mathrm{~g} / \mathrm{kg} / \mathrm{mth}$ was started. Three years later, biopsy of the enlarged axillary lymph node was performed and histopathological analysis revealed a nonspecific granulomatous reaction.

In February 2009, the patient experienced fatigue, night sweats and enlargement of the cervical lymph nodes. Chest radiography revealed left pleural effusion (Fig. 1). Pleural and lymph node biopsies were performed and pathohistological analysis revealed DLBCL in both the lymph nodes and pleura, with the following immunophenotypes: CD79 $\alpha^{+}, \mathrm{CD}^{2} 0^{+}$, $\mathrm{EMA}^{-}, \mathrm{CD}^{-}{ }^{-}, \mathrm{CD}^{-}, \mathrm{BCl}-2^{-}, \mathrm{CD} 23^{-}, \mathrm{CD}_{43}^{-/+}, \mathrm{MUM1}^{-/+}, \mathrm{Ki}^{-67^{+}}$ (in $40 \%$ of cells), Epstein-Barr virus (EBV)-, and EBV-encoded RNA (EBER)- (Fig. 2). Based on computed tomography (CT) and bone marrow biopsy findings, the patient was staged as clinical stage II B E, according to the Ann Arbor staging system. The serological viral markers for human immunodeficiency virus, hepatitis $B$ virus and hepatitis $C$ virus were negative.

${ }^{1}$ Clinic for Hematology, Clinical Center of Serbia, ${ }^{2}$ Faculty of Medicine, University of Belgrade, ${ }^{3}$ Institute for Transfusiology and Hemobiology of MMA, ${ }^{4}$ nstitute for Medical Research, University of Belgrade, Belgrade, Serbia

Correspondence: A/Prof Milena Todorovic, Professor, Clinic for Hematology, Clinical Center of Serbia, 11000 Belgrade, Serbia. bb.lena@gmail.com 


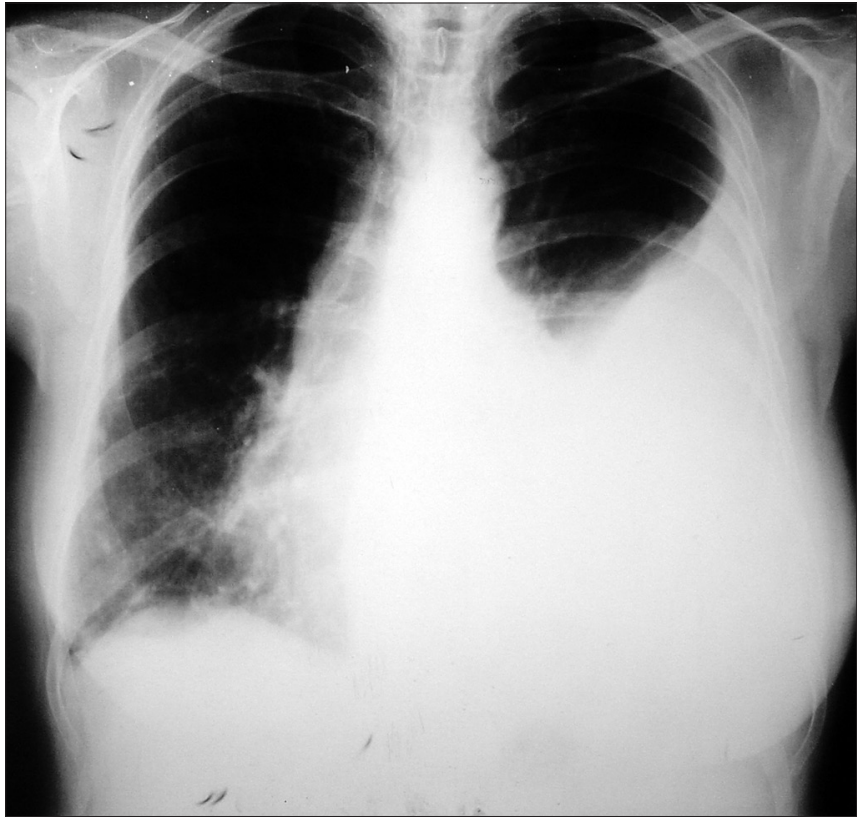

Fig. 1 Chest radiograph shows massive left pleural effusion.

The patient was admitted and underwent upper endoscopy to assess the gastric status, in addition to standard staging procedures. Pathohistological analysis of the gastric mucosal biopsy samples revealed superficial gastritis, incipient antral atrophy and the presence of Helicobacter pylori (H. pylori). We started the patient on regular IVIG substitution, triple antibiotic regimen to eradicate $H$. pylori and immunochemotherapy (R-CHOP regimen - rituximab $375 \mathrm{mg} / \mathrm{m}^{2}$ IV on Day 1; cyclophosphamide $750 \mathrm{mg} / \mathrm{m}^{2}$ IV on Day 2; hydrodoxorubicine $50 \mathrm{mg} / \mathrm{m}^{2} \mathrm{IV}$ on Day 2; vincristine $1.4 \mathrm{mg} / \mathrm{m}^{2} \mathrm{IV}$ on Day 2; prednisolone $100 \mathrm{mg}$ on Days $1-5)$. After six cycles of R-CHOP-21 without complications, the patient achieved complete remission and continued with regular IVIG treatment. However, 20 months after the last cycle of the $\mathrm{R}-\mathrm{CHOP}$ regimen, a pathohistological diagnosis of colorectal adenocarcinoma (Fig. 3), a novel malignancy, was made and hemicolectomy was performed. Unfortunately, even with full antiinfective supportive care, the patient died due to postoperative infective complications.

\section{DISCUSSION}

The innate genetic instability of lymphocytes, as well as the persistent activation and proliferation of the lymphoid system during the course of infections, enhances the risk of malignant transformation. This is evident mainly in chronic infections, immunodeficiency and autoimmune conditions, which are wellknown risk factors for lymphomas and conditions commonly found in the setting of CVID. ${ }^{(2)}$

Quinti et al reported a 12-18-fold increased incidence of malignant lymphoma development in patients with CVID. ${ }^{(8)}$ Approximately $50 \%$ of patients with CVID develop nonmalignant Iymphoid hyperplasia, presenting with lymphadenopathy, splenomegaly and/or gastrointestinal nodular hyperplasia. ${ }^{(9)}$ The morphology of lymphoid tissue in antibody-deficient patients is specific because the infection can cause atypical lymphoid hyperplasia, which is difficult to distinguish from lymphoma.
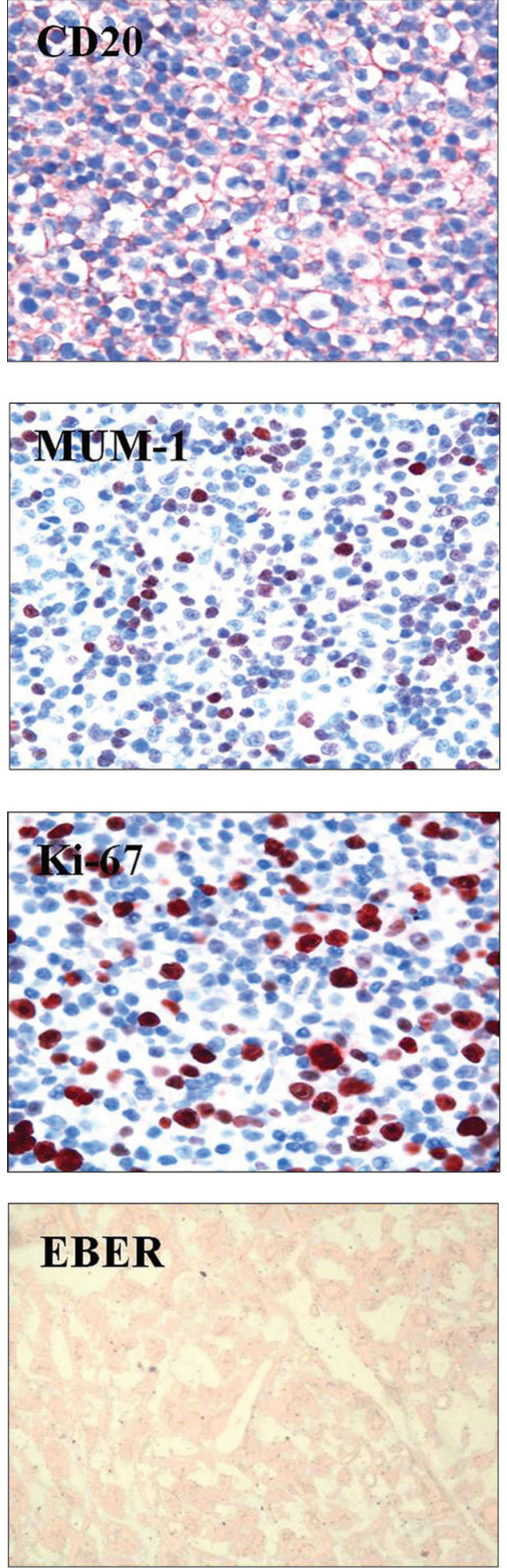

Fig. 2 Photomicrographs show the immunohistochemical patterns of expression in the tumour tissues of diffuse large B cell lymphoma - CD20 (× 60), MUM-1 (× 40), Ki-67 (× 60) and EBER (× 20).

Lymphomas that occur in association with CVID are mainly of B cell origin. ${ }^{(10)}$ So far, only one case of T cell lymphoma - T cell hepatosplenic lymphoma mimicking juvenile systemic lupus erythematosus - has been reported in the literature. ${ }^{(11)}$

Other immunodeficiency syndromes were excluded in our patient, according to the criteria by the Pan-American Group for Immunodeficiency and the European Society for Immunodeficiencies. Unlike these immunodeficiency syndromes, 


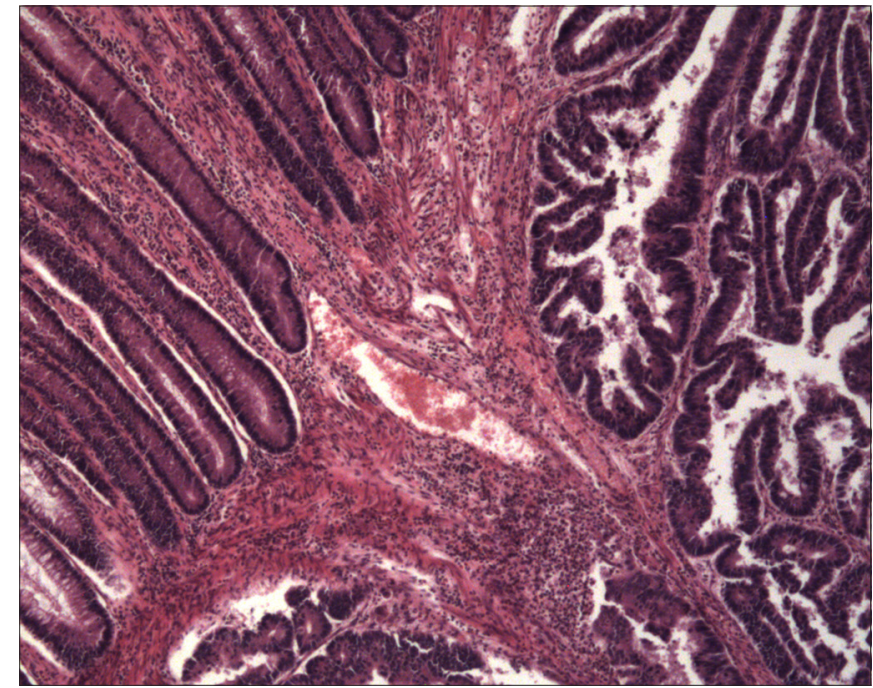

Fig. 3 Photomicrograph of the colorectal adenocarcinoma sample shows normal and infiltrated rectal mucosa with tumour cells (Haematoxylin \& eosin, $\times 50)$

malignant lymphoproliferations associated with CVID are

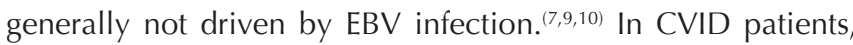
non-Hodgkin's lymphomas occur more frequently than Hodgkin's lymphomas. ${ }^{(12)}$ Endoscopy, a noninvasive screening test for gastrointestinal pathology, is recommended for the assessment of gastric status in CVID patients and for detection of early-stage malignancy. Our patient was evaluated based on the existence of an eventual lymphoma in the upper gastrointestinal tract; however, only chronic gastritis with $H$. pylori infection was found. An antibiotic regimen to eradicate $H$. pylori is the treatment of choice, despite variable success due to previous prolonged use of antibiotics.

Colorectal adenocarcinoma was diagnosed in our patient 20 months after successful DLBCL therapy and remission. All inflammatory, infectious and other malignant gastrointestinal disorders were excluded in our patient, although they are highly prevalent in the course of CVID. ${ }^{(3,4)}$ These disorders include nodular lymphoid hyperplasia, inflammatory bowel disease, and nonspecific malabsorption. However, solid tumours seldom occur in the setting of CVID, and in particular, gastric cancer rarely develops in association with this immunodeficiency. ${ }^{(13,14)}$ Furthermore, only one case of hepatocellular carcinoma associated with CVID has been reported in the absence of pre-existing liver disease. ${ }^{(15)}$

Interestingly, our patient initially had uterine adenocarcinoma, a malignant disease, at 32 years old, more than 20 years before the development of DLBCL. On two occasions, she was also diagnosed with basal cell carcinoma, a secondary malignancy due to CVID, which was not recognised at that time. To the best of our knowledge, this is the first case of CVID associated with multiple solid tumours and aggressive B cell lymphoma.

\section{ACKNOWLEDGEMENTS}

This work was supported by the Ministry of Science of Serbia (Project no. 41004).

\section{REFERENCES}

1. Park MA, Li JT, Hagan JB, Maddox DE, Abraham RS. Common variable immunodeficiency: a new look at an old disease. Lancet 2008; 372:489-502

2. Notarangelo LD. Primary immunodeficiences. J Allergy Clin Immunol 2010; 125 (2 Suppl 2):182-94.

3. Schroeder HW. Primary antibody deficiencies. In: Rich RR, Fleisher TA, Shearer WT, et al (Eds). Clinical Immunology-Principles and Practice. 3rd ed. London: Elsevier Limited, 2008.

4. da Silva SP, Resnick E, Lucas M, et al. Lymphoid proliferations of indeterminate malignant potential arising in adults with common variable immunodeficiency disorders: unusual case studies and immunohistological review in the light of possible causative events. J Clin Immunol 2011; 31:784-91.

5. Cunningham-Rundless C, Bodian C. Common variable immunodeficiency: clinical and immunological features of 248 patients. Clin Immunol 1999; 92:34-48.

6. Van der Hilst JC, Smits BW, van der Meer JW. Hypogammaglobulinaemia: cumulative experience in 49 patients in a tertiary care institution. Neth J Med 2002; 60:140-7.

7. Conley ME, Notarangelo LD, Etzioni A. Diagnostic criteria for primary immunodeficiencies. Representing PAGID (Pan-American Group for Immunodeficiency) and ESID (European Society for Immunodeficiencies). Clin Immunol 1999; 93:190-7.

8. Quinti I, Soresina A, Spadaro G, et al. Long-term follow-up and outcome of a large cohort of patients with common variable immunodeficiency. J Clin Immunol 2007; 27:308-16.

9. Sander CA, Medeiros LJ, Weiss LM, et al. Lymphoproliferative lesions in patients with common variable immunodeficiency syndrome. Am J Surg Pathol 1992; 16:1170-82

10. Gottesman SR, Haas D, Ladanyt M, Amorosi EL. Peripheral T cell lymphoma in a patient with common variable immunodeficiency: case report and literature review. Leuk Lymphoma 1999; 32:589-95.

11. Jesus AA, Jacob CM, Silva CA, et al. Common variable immunodeficiency associated with hepatosplenic T-cell lymphoma mimicking juvenile systemic lupus erythematosus. Clin Dev Immunol 2011; 2011:428703.

12. Scott-Taylor TH, Green MR, Raeiszadeh M, Workman S, Webster AD. Defective maturation of dendritic cells in common variable immunodeficiency. Clin Exp Immunol 2006; 145:420-7.

13. Fatemi R, Moadab Y, Mousavi S, Zali M. Advanced gastric cancer, a very rare complication of Common Variable Immunodeficiency: a case report. Gastoenterol Hepatol Bed Bench 2008; 1:99-101.

14. Yap YL, So JB. Gastric adenocarcinoma occurring in a young patient with common variable immunodeficient syndrome. Singapore Med J 2009; 50:e201-3.

15. Gandhi K, Parikh P, Aronow WS, et al. A case of explosive progression of hepatocellular carcinoma in a patient with common variable immunodeficiency (CVID). J Gastrointest Cancer 2010; 41:281-4. 